\title{
INDIVIDUAL MONITORING OF INTERNAL EXPOSURE FOR NUCLEAR MEDICINE WORKERS IN SWITZERLAND
}

\author{
S. Baechler ${ }^{1, *}$, N. Stritt ${ }^{2}$ and F. O. Bochud ${ }^{1}$ \\ ${ }^{1}$ Institute of Radiation Physics, University Hospital Center and University of Lausanne, Lausanne, \\ Switzerland \\ ${ }^{2}$ Federal Office of Public Health, Bern, Switzerland \\ *Corresponding author: sebastien.baechler@chuv.ch
}

\begin{abstract}
Monitoring of internal exposure for nuclear medicine workers requires frequent measurements due to the short physical halflives of most radionuclides used in this field. The aim of this study was to develop screening measurements performed at the workplace by local staff using standard laboratory instrumentation, to detect whether potential intake has occurred. Such measurements do not enable to determine the committed effective dose, but are adequate to verify that a given threshold is not exceeded. For radioiodine, i.e. ${ }^{123} \mathrm{I},{ }^{124} \mathrm{I},{ }^{125} \mathrm{I}$ and ${ }^{131} \mathrm{I}$, a calibrated surface contamination monitor is placed in front of the thyroid to detect whether the activity threshold has been exceeded. For radionuclides with very short physical half-lives $(\leq 6 \mathrm{~h})$, such as ${ }^{99 \mathrm{~m}} \mathrm{Tc}$ and those used in positron emission tomography imaging, i.e. ${ }^{11} \mathrm{C},{ }^{15} \mathrm{O},{ }^{18} \mathrm{~F}$ and ${ }^{68} \mathrm{Ga}$, screening procedures consist in performing daily measurements of the ambient dose rate in front of the abdomen. Other gamma emitters used for imaging, i.e. ${ }^{67} \mathrm{Ga},{ }^{111} \mathrm{In}$ and ${ }^{201} \mathrm{Tl}$, are measured with a scintillation detector located in front of the thorax. For pure beta emitters, i.e. ${ }^{90} \mathrm{Y}$ and ${ }^{169} \mathrm{Er}$, as well as beta emitters with low-intensity gamma rays, i.e. ${ }^{153} \mathrm{Sm},{ }^{177} \mathrm{Lu},{ }^{186} \mathrm{Re}$ and ${ }^{188} \mathrm{Re}$, the procedure consists in measuring hand contamination immediately after use. In Switzerland, screening procedures have been adopted by most nuclear medicine services since such measurements enable an acceptable monitoring while taking into account practical and economic considerations.
\end{abstract}

\section{INTRODUCTION}

Workers who may accumulate an effective dose $>1$ $\mathrm{mSv} \mathrm{y}^{-1}$ are considered as occupationally exposed to ionising radiation. Unless the internal exposure contributes to $<10 \%$ of the total, i.e. external and internal, annual effective dose or to $<0.1 \mathrm{mSv} \mathrm{y}^{-1}$, individual monitoring for internal exposure is required ${ }^{(1)}$. As illustrated in Figure 1, the monitoring of Swiss workers with a risk of intake is based on a two-stage measurement process as follows: $:^{(1,2)}$

(i) 'screening measurements' performed at the workplace by local staff to detect whether potential intake has occurred; and

(ii) 'intake measurements' performed by an approved dosimetry service to determine the committed effective dose, $E_{50}$, in the case of positive screening results.

Screening measurements are particularly suitable for monitoring nuclear medicine workers since the short half-lives of most radionuclides used in this field impose frequent measurements. In contrast to intake measurements, screening measurements are meant to be performed on site using commonly available laboratory instruments and thus do not require complex and expensive equipments for accurate quantitative analysis, such as whole body counters.

The aim of this work was to develop practical screening procedures for most radionuclides used in nuclear medicine, including gamma emitters and $\beta^{+}$ emitters used for imaging, as well as $\beta^{-}$emitters used for therapy.

\section{MATERIALS AND METHODS}

The screening procedure consists of a simple, rough measurement that does not enable one to calculate $E_{50}$, but is sufficient to verify that a given threshold is not surpassed. The screening threshold is chosen to detect and not miss significant intake, as well as to avoid standard intake measurement in the case of negligible intake. The threshold is specific to the radionuclide and is defined in such a way that the annual $E_{50}$ is $<1 \mathrm{mSv}$, in most cases, if the threshold is never exceeded over the year. The dose criterion is generally based on the inhalation pathway in order to address conservative exposure scenarios. Assuming that intake occurs in the middle of the screening interval $\tau$, the screening threshold $S$ (in $\mathrm{Bq}$ ) is given by the following expression:

$$
S=\frac{E_{50}}{N(\tau)} \cdot \frac{m(\tau / 2)}{e_{\mathrm{inh}}}
$$

where $N(\tau)$ is the number of screening measurements per year, $m(\tau / 2)$ is the retention fraction given in ICRP $78^{(3)}$ and ${ }^{(4)}$, i.e. the fraction of the activity remaining in the whole body or in an organ at a time $t=\tau / 2$, derived from standard biokinetic 


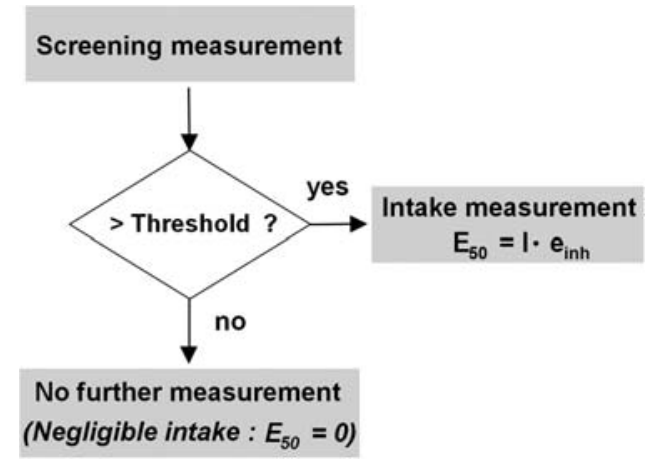

Figure 1. Concept for monitoring Swiss workers with a risk of internal contamination based on (i) screening measurements and (ii) intake measurements.

models, and $e_{\text {inh }}$ is the effective dose coefficient for inhalation obtained from ICRP $68^{(5)}$. Four groups of radionuclides are differentiated to develop specific screening procedures: radioiodine, gamma emitters, $\beta^{+}$emitters and $\beta^{-}$emitters.

\section{Screening procedure for radioiodine}

Threshold values for ${ }^{123} \mathrm{I},{ }^{124} \mathrm{I},{ }^{125} \mathrm{I}$ and ${ }^{131} \mathrm{I}$ are determined according to Equation (1). The retention of activity in the thyroid is to be considered in the case of iodine. For the screening procedure, a surface contamination monitor (SCM), which is available in any nuclear medicine service, is placed in front of the thyroid to detect whether the threshold is exceeded. The calibration procedure of the SCM used for screening measurements is described elsewhere ${ }^{(6)}$. Briefly, the method consists in measuring the response of the SCM to a known activity of radioiodine located in the thyroid of a standard neck phantom. The calibration factor in becquerel per count per second (cps) is then obtained, and the threshold can be determined in cps specifically for each SCM.

\section{Screening procedure for gamma emitters}

For ${ }^{67} \mathrm{Ga},{ }^{111} \mathrm{In}$ and ${ }^{201} \mathrm{Tl}$, threshold values are based on the whole body retention. Screening measurements are performed using a lung monitor (LM) that consists of a properly calibrated scintillation detector positioned in front of the chest. The calibration procedure is based on the response of the LM to a known activity located in a simple trunk phantom. The threshold is then determined in cps for a given LM.

For ${ }^{99 \mathrm{~m}} \mathrm{Tc}$, because of the very short half-life $\left(T_{1 / 2}=6 \mathrm{~h}\right)$, daily measurements are required. Therefore, a very simple screening approach based on ambient dose rate measurement is introduced. First, it was assumed that after a few hours the radionuclide is mainly localised in the abdomen. Positioning a dose rate meter in front of the abdomen (at stomach level) leads to a measured ambient dose rate $\dot{H}^{*}(10)$ which may be related to the activity threshold $S$ as follows:

$$
\begin{aligned}
\dot{H}^{*}(10) & =S \cdot \frac{\dot{h}(10)}{r^{2}} \\
& =\frac{E_{50}}{N(\tau)} \cdot \frac{2^{-(\tau / 2) / T_{1 / 2}}}{e_{i n h}} \cdot k \cdot \frac{\dot{h}(10)}{r^{2}}
\end{aligned}
$$

where $\dot{h}(10)$ is the effective dose rate coefficient for external irradiation ${ }^{(7,8)}$ and $r$ is the distance between the source, i.e. the abdomen, and the detector $(\sim 7 \mathrm{~cm})$. The attenuation within the body is assumed negligible. The correction factor $k$ takes into account for a measurement in a non-point-source geometry due to the distribution of the radionuclide within the body. The factor $k$ was analytically estimated by the ratio of fluence rates between simple planar sources and a point source at a distance $r$. For various planar sources mimicking different retention patterns in the abdominal region, $k$-values between 0.2 and 0.8 were found and a generic value of 0.5 was finally adopted. For daily measurements, $N(\tau)$ corresponds to the number of working days per year, i.e. 200.

\section{Screening procedure for $\boldsymbol{\beta}^{+}$emitters}

The ambient dose rate approach described in Equation (2) is also suitable for $\beta^{+}$emitters that show low values of $e_{\text {inh }}$ (low radiotoxicity) and high values of $\dot{h}^{*}(10)$ (strong exposure rate due to $511 \mathrm{keV}$ annihilation radiation). However, since $\beta^{+}$emitters used for positron emission tomography are even shorter-lived radionuclides than ${ }^{99 \mathrm{~m}} \mathrm{Tc}$, screening measurements are required twice a day, in the middle and at the end of the working day. For ${ }^{15} \mathrm{O}$, monitoring of contamination in the breathing air must be implemented at the workplace because of the only 2 min half-life. Screening measurements are then only performed if a given air contamination threshold has been exceeded (alarm).

\section{Screening procedure for $\boldsymbol{\beta}^{-}$emitters}

For pure $\beta^{-}$emitters, i.e. ${ }^{90} \mathrm{Y}$ and ${ }^{169} \mathrm{Er}$, as well as beta emitters with low-intensity gamma rays, i.e. ${ }^{153} \mathrm{Sm},{ }^{177} \mathrm{Lu},{ }^{186} \mathrm{Re}$ and ${ }^{188} \mathrm{Re}$, screening measurements are usually combined with standard intake measurements, i.e. liquid scintillation counting of activity in urine. However, because of the short halflife of $\beta^{-}$emitters used in nuclear medicine, weekly measurements would be required. Furthermore, because of the relatively high radiotoxicity of those $\beta^{-}$emitters, the activity threshold to be measured is 


\section{S. BAECHLER ET AL.}

so low that a chemical separation of the radionuclide in the urine is often required before measurement. Such a screening method is clearly cost-ineffective and unrealistic for monitoring intake of $\beta^{-}$emitters.

Since most radiopharmaceuticals labelled with $\beta^{-}$emitters are non-volatile, one may consider the use of ingestion instead of inhalation as the relevant pathway. The screening procedure is then simply based on measurements of hand contamination immediately after each use of the radionuclide. The screening threshold $S$ (in $\mathrm{Bq} \mathrm{cm}{ }^{-2}$ ), is defined in such a way that a daily ingestion of $1 \%$ of the threshold over $100 \mathrm{~cm}^{2}$ of the hands leads to $E_{50}$ of $\sim 1 \mathrm{mSv}$. The threshold is then calculated as follows:

$$
S=\frac{E_{50}}{N(\tau) \cdot e_{\text {ing }} \cdot 100} \cdot \frac{1}{1 \%}
$$

where $e_{\text {ing }}$ is the effective dose coefficient for ingestion $^{(4)}$. A daily use is assumed and $N(\tau)$ is set to 200 .

\section{RESULTS AND DISCUSSION}

Practical screening procedures for most radionuclides used in nuclear medicine are summarised in Table 1. The different approaches applied to radioiodine, gamma emitters, $\beta^{+}$emitters and $\beta^{-}$emitters are discussed.

\section{Screening procedures for radioiodine}

For ${ }^{123} \mathrm{I},{ }^{124} \mathrm{I},{ }^{125} \mathrm{I}$ and ${ }^{131} \mathrm{I}$, the screening procedure consists in measuring the activity threshold using a calibrated SCM placed in front of the thyroid. For ${ }^{123} \mathrm{I}$ and ${ }^{125} \mathrm{I}$, the threshold given in Table 1 corresponds to an intake that leads to a minimum detectable $E_{50}$ of $\sim 1 \mathrm{mSv}$, considering repetitive intake in the middle of the screening interval. For ${ }^{124} \mathrm{I}$ and ${ }^{131} \mathrm{I}$, it is not the case and, according to Equation (1), the threshold for a weekly screening should be 260 and $190 \mathrm{~Bq}$, respectively. On the other hand, typical SCMs used for screening have a minimum detectable activity of $\sim 3000 \mathrm{~Bq}$ for ${ }^{124} \mathrm{I}$ and 2000 $\mathrm{Bq}$ for ${ }^{131} \mathrm{I}$. Therefore, in practice, a threshold of $3000 \mathrm{~Bq}$ is used for ${ }^{124} \mathrm{I}$ and $2000 \mathrm{~Bq}$ for ${ }^{131} \mathrm{I}$, with a screening interval of 1 week. Although the dose limit of $1 \mathrm{mSv} \mathrm{y}^{-1}$ is not strictly guaranteed, this choice is considered optimal since it ensures a low rate of false positives and, because of the high measurement frequency, a high probability of detecting a significant intake.

\section{Screening procedures for gamma emitters}

For ${ }^{67} \mathrm{Ga},{ }^{111} \mathrm{In}$ and ${ }^{201} \mathrm{Tl}$, screening measurements are performed using a properly calibrated LM. Since an LM is often not available in nuclear medicine
Table 1. Screening procedures for most commonly used radionuclides in nuclear medicine with the method of measurement, the screening interval, the threshold value and the minimum detectable annual $E_{50}\left(E_{50, \mathrm{~min}}\right)$.

\begin{tabular}{|c|c|c|c|c|}
\hline Nuclide & Method & Interval & Threshold & $\begin{array}{r}E_{50, \min } \\
\text { (in } \mathrm{mSv}\end{array}$ \\
\hline${ }^{11} \mathrm{C}$ & $\mathrm{DRM}^{\mathrm{a}}$ & $4 \mathrm{~h}$ & $1 \mu \mathrm{Sv} \mathrm{h}^{-1}$ & 5.0 \\
\hline${ }^{15} \mathrm{O}$ & $\mathrm{DRM}^{\mathrm{a}}$ & by alarm ${ }^{\mathrm{e}}$ & $1 \mu \mathrm{Sv} \mathrm{h}^{-1}$ & 2.9 \\
\hline${ }^{18} \mathrm{~F}$ & $\mathrm{DRM}^{\mathrm{a}}$ & $4 \mathrm{~h}$ & $1 \mu \mathrm{Sv} \mathrm{h}^{-1}$ & 4.8 \\
\hline${ }^{67} \mathrm{Ga}$ & $\mathrm{LM}^{\mathrm{b}}$ & $7 \mathrm{~d}$ & $5500 \mathrm{~Bq}$ & 1.0 \\
\hline${ }^{68} \mathrm{Ga}$ & $\mathrm{DRM}^{\mathrm{a}}$ & $4 \mathrm{~h}$ & $1 \mu \mathrm{Sv} \mathrm{h}^{-1}$ & 7.1 \\
\hline${ }^{90} \mathrm{Y}$ & $\mathrm{HCM}^{\mathrm{c}}$ & each use & $3000 \mathrm{~Bq} \mathrm{~cm}^{-2}$ & 1.6 \\
\hline${ }^{99 \mathrm{~m}} \mathrm{Tc}$ & $\mathrm{DRM}^{\mathrm{a}}$ & $12 \mathrm{~h}$ & $1 \mu \mathrm{Sv} \mathrm{h}^{-1}$ & 5.3 \\
\hline${ }^{111} \mathrm{In}$ & $\mathrm{LM}^{\mathrm{b}}$ & $7 \mathrm{~d}$ & $5000 \mathrm{~Bq}$ & 1.0 \\
\hline${ }^{123} \mathrm{I}$ & $\mathrm{SCM}^{\mathrm{d}}$ & $1 \mathrm{~d}$ & $1400 \mathrm{~Bq}$ & 1.0 \\
\hline${ }^{124} \mathrm{I}$ & $\operatorname{SCM}^{\mathrm{d}}$ & $7 \mathrm{~d}$ & $3000 \mathrm{~Bq}$ & 11.5 \\
\hline${ }^{125} \mathrm{I}$ & $\mathrm{SCM}^{\mathrm{d}}$ & $30 \mathrm{~d}$ & $1300 \mathrm{~Bq}$ & 1.0 \\
\hline${ }^{131} \mathrm{I}$ & $\mathrm{SCM}^{\mathrm{d}}$ & $7 \mathrm{~d}$ & $2000 \mathrm{~Bq}$ & 10.5 \\
\hline${ }^{153} \mathrm{Sm}$ & $\mathrm{HCM}^{\mathrm{c}}$ & each use & $3000 \mathrm{~Bq} \mathrm{~cm}^{-2}$ & 0.4 \\
\hline${ }^{169} \mathrm{Er}$ & $\mathrm{HCM}^{\mathrm{c}}$ & each use & $10000 \mathrm{~Bq} \mathrm{~cm}^{-2}$ & 0.7 \\
\hline${ }^{177} \mathrm{Lu}$ & $\mathrm{HCM}^{\mathrm{c}}$ & each use & $3000 \mathrm{~Bq} \mathrm{~cm}^{-2}$ & 0.3 \\
\hline${ }^{186} \mathrm{Re}$ & $\mathrm{HCM}^{\mathrm{c}}$ & each use & $3000 \mathrm{~Bq} \mathrm{~cm}^{-2}$ & 0.9 \\
\hline${ }^{188} \mathrm{Re}$ & $\mathrm{HCM}^{\mathrm{c}}$ & each use & $3000 \mathrm{~Bq} \mathrm{~cm}^{-2}$ & 0.8 \\
\hline${ }^{201} \mathrm{Tl}$ & $\mathrm{LM}^{\mathrm{b}}$ & $14 \mathrm{~d}$ & $55000 \mathrm{~Bq}$ & $\begin{array}{l}0.0 \\
1.0\end{array}$ \\
\hline
\end{tabular}

${ }^{\mathrm{a}} \mathrm{DRM}$, dose rate monitor (abdomen/stomach).

${ }^{\mathrm{b}} \mathrm{LM}$, lung monitor.

${ }^{\mathrm{c}} \mathrm{HCM}$, hand contamination monitor (over $100 \mathrm{~cm}^{2}$ ).

${ }^{\mathrm{d}} \mathrm{SCM}$, surface contamination monitor (thyroid).

${ }^{\mathrm{e}} \mathrm{By}$ alarm, air contamination at workplace above $4000 \mathrm{~Bq} \mathrm{~m}^{-3}$.

Table 2. Dose rate approach for screening measurements of gamma emitters and $\boldsymbol{\beta}^{+}$emitters.

\begin{tabular}{llccc}
\hline Nuclide & $T_{1 / 2, \text { phys }}$ & $\begin{array}{c}e_{\text {inh }}(\text { in Sv } \\
\left.\mathrm{Bq}^{-1}\right)\end{array}$ & $\begin{array}{c}\dot{h}(10) \text { (in } \\
\text { mSv m } \\
\text { h GBq) }\end{array}$ & $\begin{array}{c}\dot{H}^{*}(10) \text { (in } \\
\left.\mu S v \mathrm{~h}^{-1}\right)\end{array}$ \\
\hline${ }^{11} \mathrm{C}$ & $20 \mathrm{~min}$ & $3.2 \times 10^{-12}$ & 0.160 & $0.20^{\mathrm{a}}$ \\
${ }^{15} \mathrm{O}$ & $2 \mathrm{~min}$ & $6.7 \times 10^{-13}$ & 0.160 & $0.34^{\mathrm{b}}$ \\
${ }^{18} \mathrm{~F}$ & $110 \mathrm{~min}$ & $9.3 \times 10^{-11}$ & 0.160 & $0.21^{\mathrm{a}}$ \\
${ }^{68} \mathrm{Ga}$ & $68 \mathrm{~min}$ & $8.1 \times 10^{-11}$ & 0.149 & $0.14^{\mathrm{a}}$ \\
${ }^{99} \mathrm{~m} \mathrm{Tc}$ & $6 \mathrm{~h}$ & $2.9 \times 10^{-11}$ & 0.025 & $0.19^{\mathrm{c}}$ \\
${ }^{67} \mathrm{Ga}$ & $78 \mathrm{~h}$ & $2.8 \times 10^{-10}$ & 0.022 & $0.04^{\mathrm{c}}$ \\
${ }^{111} \mathrm{In}$ & $67 \mathrm{~h}$ & $3.1 \times 10^{-10}$ & 0.082 & $0.13^{\mathrm{c}}$ \\
${ }^{201} \mathrm{Tl}$ & $72 \mathrm{~h}$ & $7.6 \times 10^{-10}$ & 0.018 & $0.11^{\mathrm{c}}$ \\
\hline
\end{tabular}

${ }^{\mathrm{a}}$ Screening interval of $4 \mathrm{~h}$.

${ }^{\mathrm{b}}$ Post-alarm interval of $15 \mathrm{~min}$. (2 alarms per day)

${ }^{\mathrm{c}}$ Screening interval of $12 \mathrm{~h}$ (daily measurement).

services, the use of the dose rate approach for those nuclides is also being considered. Corresponding dose rate thresholds calculated according to Equation (2) are given in Table 2. Note that in the case of ${ }^{99 \mathrm{~m}} \mathrm{Tc}$, although Equation (2) yields a value of $0.19 \mu \mathrm{Sv} \mathrm{h}^{-1}$, a practical threshold of $1 \mu \mathrm{Sv} \mathrm{h}^{-1}$ has been chosen to avoid false positives while keeping a high probability of detecting a significant intake. 


\section{Screening procedures for $\boldsymbol{\beta}^{+}$emitters}

The screening procedure for ${ }^{11} \mathrm{C},{ }^{15} \mathrm{O},{ }^{18} \mathrm{~F}$ and ${ }^{68} \mathrm{Ga}$ consists in frequent measurement of the ambient dose rate in front of the stomach. Similar to ${ }^{99 \mathrm{~m}} \mathrm{Tc}$, practical threshold values have been set to $1 \mu \mathrm{Sv} \mathrm{h}^{-1}$ for all those radionuclides even though theoretical threshold values given in Table 2 range between 0.14 and $0.34 \mu \mathrm{Sv} \mathrm{h}^{-1}$.

\section{Screening procedures for $\boldsymbol{\beta}^{-}$emitters}

For ${ }^{90} \mathrm{Y},{ }^{153} \mathrm{Sm},{ }^{169} \mathrm{Er},{ }^{177} \mathrm{Lu},{ }^{186} \mathrm{Re}$ and ${ }^{188} \mathrm{Re}$, the screening procedure consists in measuring the contamination of hands immediately after handling, after removal of gloves. Threshold values given in Table 1 are not exactly derived from Equation (3). For practical reasons, threshold values were set to 1000 times the reference value for the maximum permissible level of surface contamination given in the Swiss Ordinance on Radiation Protection ${ }^{(7)}$. As a result, $E_{50}$ ranges between 0.3 and $0.9 \mathrm{mSv}$ for all those emitters except for ${ }^{90} \mathrm{Y}(1.6 \mathrm{mSv})$.

\section{Application in nuclear medicine}

Screening procedures for most radionuclides used in nuclear medicine are now included in the Swiss Personal Dosimetry Ordinance ${ }^{(1)}$ as an alternative method to intake measurements. If the screening threshold is exceeded, then a contact with an approved internal dosimetry service must be established to assess $E_{50}$ using thyroid counting (radioiodine), whole body counting (gamma emitters) or urine analysis ( $\beta^{-}$emitters). For ${ }^{11} \mathrm{C},{ }^{15} \mathrm{O},{ }^{18} \mathrm{~F},{ }^{68} \mathrm{Ga}$ and ${ }^{99 \mathrm{~m}} \mathrm{Tc}$, screening measurements are mandatory since intake measurements are not possible because of the very short physical half-lives. Note that the threshold for ${ }^{11} \mathrm{C},{ }^{15} \mathrm{O},{ }^{18} \mathrm{~F}$ and ${ }^{68} \mathrm{Ga}$ has been set to $0.1 \mu \mathrm{Sv} \mathrm{h}^{-1}$ in the current Swiss Personal Dosimetry Ordinance and might be adapted to $1 \mu \mathrm{Sv} \mathrm{h}^{-1}$ in the future. Usually, nuclear medicine services are not interested in routine monitoring with standard intake measurements because of the strict quality control requirements and demands concerning the ability to determine $E_{50}$. Practically, screening procedures of any radionuclide used in nuclear medicine can be achieved by a single measurement based on an instrument equipped with properly calibrated SCMs for the hands and the thyroid, and a dose rate meter positioned at the stomach level. In Switzerland, all results of screening measurements must be locally registered. Individuals who are monitored for internal exposure by screening measurements are not registered in the National Dose Registry unless an intake measurement has been performed following a positive screening ${ }^{(9)}$. In case of continuous negative screening over the year, $E_{50}$ is recorded as zero in the individual dose document.

\section{CONCLUSIONS}

Screening measurements for detecting potential radioactivity intake by nuclear medicine workers enable an acceptable monitoring while taking into account practical and economic considerations. Since screening measurements are performed directly at the workplace with standard laboratory equipment, either a contamination monitor or a dose rate meter, they have been implemented in most nuclear medicine services in Switzerland at reasonable cost. The authority is currently auditing those services to ensure the proper execution of screening measurements.

\section{ACKNOWLEDGEMENTS}

The authors wish to thank the members of the Swiss Expert Group for Personal Dosimetry who contributed to this work

\section{REFERENCES}

1. Swiss Personal Dosimetry Ordinance, SR814.501.43, 7 October 1999.

2. Wernli, C., Boschung, M., Lauffenburger, T., Mini, R., Stoll, E., Valley, J.-F. and Zeller, W. Concept for internal dosimetry and approval of internal dosimetry services in Switzerland. Radiat. Prot. Dosim. 53, 95-97 (1994).

3. International Commission on Radiological Protection. Individual monitoring for internal exposure of workers. Replacement of ICRP Publication 54. ICRP Publication 78. Ann. ICRP 27(3-4) Pergamon Press (1998).

4. Potter, C. A. Intake retention fractions developed from models used in the determination of dose coefficients developed for ICRP publication 68-particulate inhalation. Health Phys. 83, 594-789 (2002).

5. International Commission on Radiological Protection. Dose coefficients for intakes of radionuclides by workers. Replacement of ICRP Publication 61. ICRP Publication 68. Ann. ICRP 24(4) Pergamon Press (1995).

6. Bailat, C., Buchillier, T., Baechler, S. and Bochud, F. Calibration of surface contamination monitor for the detection of iodine incorporation in the thyroid gland, this issue of radiation protection dosimetry.

7. Swiss Ordinance on Radiation Protection, SR814.501, 22 June (1994).

8. Petoussi, N. et al. 'Dose distributions in the ICRU sphere for mono-energetic photons and electrons and for ca. 800 radionuclides'. GSF-Bericht 7/93, Forschungszentrum für Umwelt und Gesundheit $\mathrm{GmbH}$, Neuherberg (1993).

9. Frei, D. et al. Integration of external and internal dosimetry in Switzerland. Radiat. Prot. Dosim. 125, 47-51 (2007). 